\title{
Raman Lidar Handbook
}

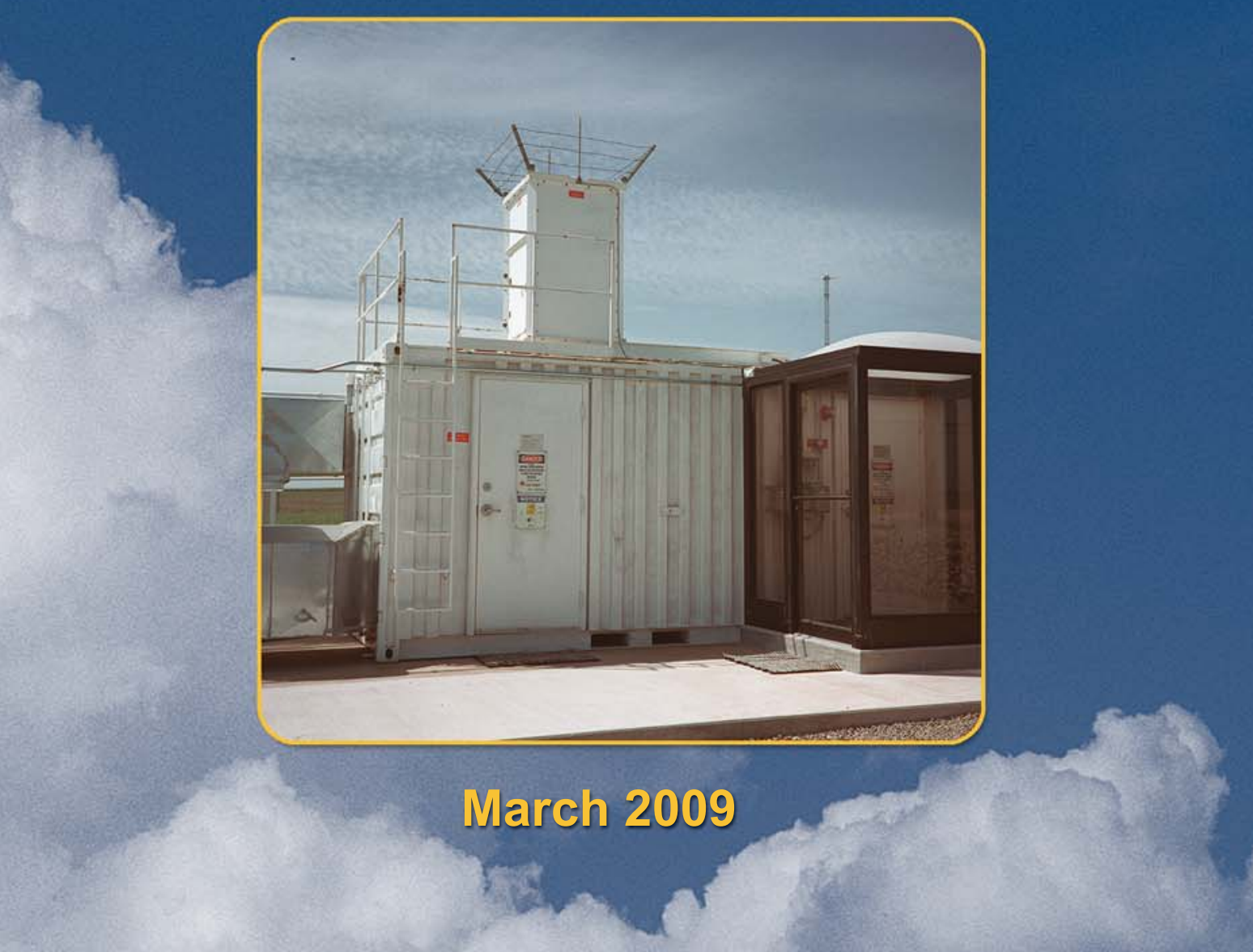

Work supported by the U.S. Department of Energy Office of Science, Office of Biological and Environmental Research 


\section{Raman Lidar (RL) Handbook}

March 2009

R. K. Newsom

Work supported by the U.S. Department of Energy, Office of Science, Office of Biological and Environmental Research 


\section{Contents}

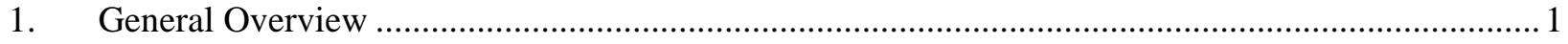

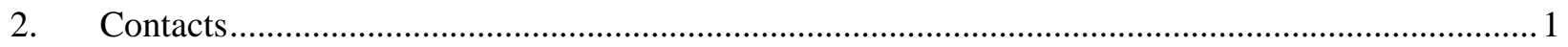

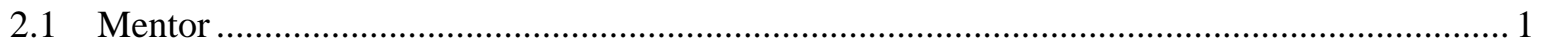

2.2 Instrument Developer ………………………………………………………………1 1

3. Deployment Locations and History .......................................................................................

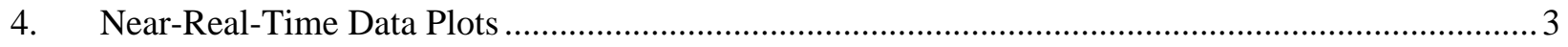

5. Data Description and Examples ……………………..........................................................

5.1 Data File Contents .................................................................................................... 4

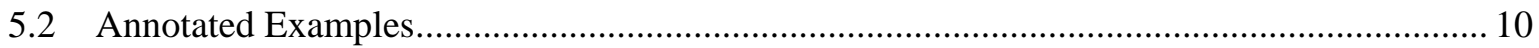

5.3 User Notes and Known Problems …………………………………………………….... 14

$5.4 \quad$ Frequently Asked Questions ……………………………………………………………. 14

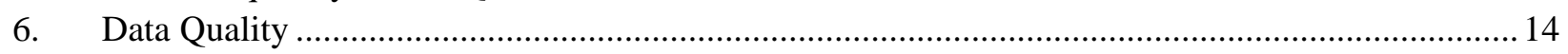

6.1 Data Quality Health and Status ………………………………………………………. 14

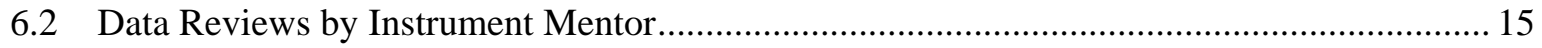

6.3 Data Assessments by Site Scientist/Data Quality Office ………………………………….... 15

6.4 Value-Added Procedures...................................................................................................... 15

6.5 Quality Measurement Experiments .................................................................................... 16

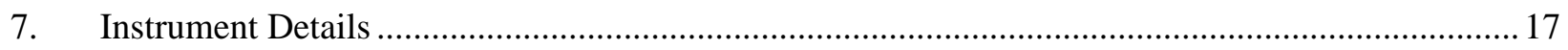

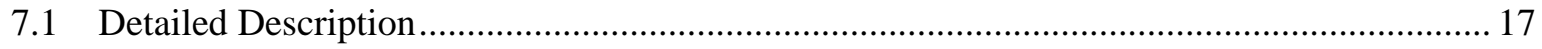

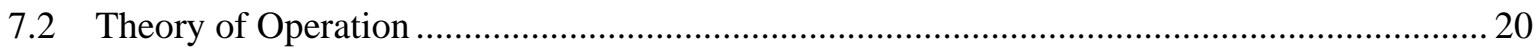

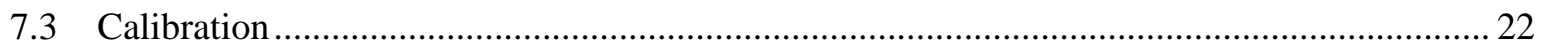

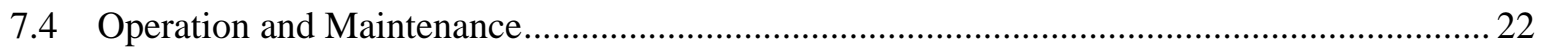

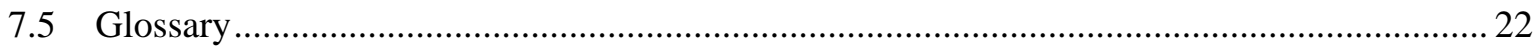

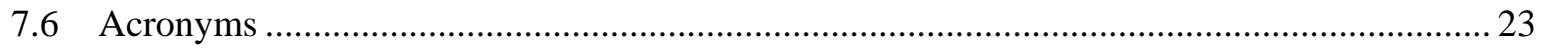

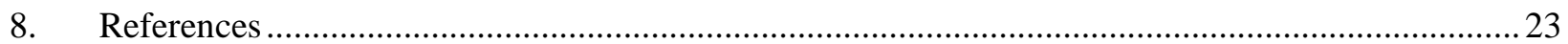




\section{Figures}

1. SGPRL Uptime from 1998 to 2009 and significant system upgrade and milestones......................... 3

2. Profiles of mean normalized bias in the RL relative to the radiosonde water vapor mixing ratio measurements for nighttime and daytime soundings. ................................................................. 7

3. Time-height cross sections of photon count rates from the WFOV elastic channel, and the NFOV elastic channel, on 14 September 2007.

4. Time-height cross sections of photon count rates from the WFOV nitrogen channel, and the NFOV nitrogen channel, on 14 September 2007.

5. Time-height cross sections of photon count rates from the WFOV water vapor channel, and the NFOV water vapor channel, on 14 September 2007.

6. Calibrated ASR data from 16 August 2007, and NFOV ASR data for the same day with no overlap correction applied.

7. Example showing artifacts in the ASR data due to FOV merging................................................13

8. Example of water vapor mixing derived from SGPRL measurements............................................ 14

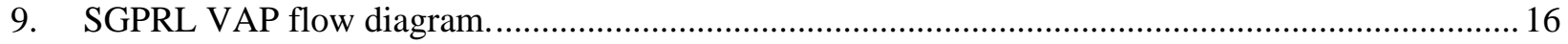

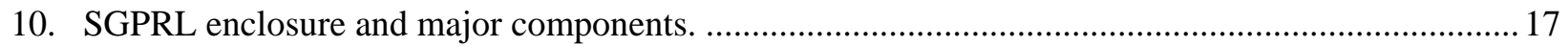

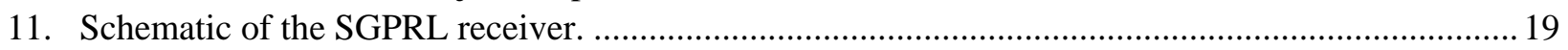

12. Schematic of the theory of operation of the Raman lidar. ............................................................. 21

\section{Tables}

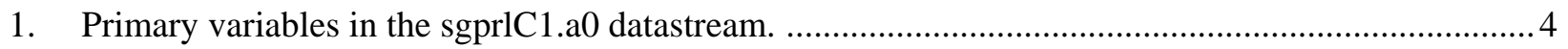

2. Primary variables in the sgprlprofmerge1turnC1 datastream. ....................................................5

3. Primary variables in the sgp10rlprofasr1ferrC1 datastream... .................................................... 5

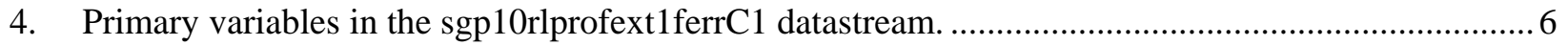

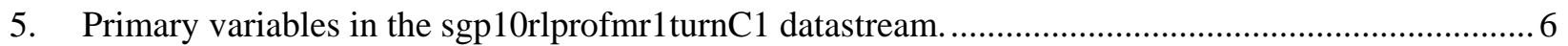

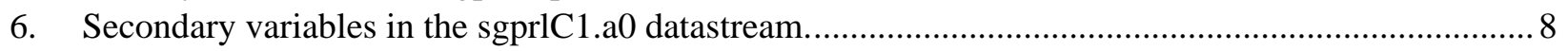

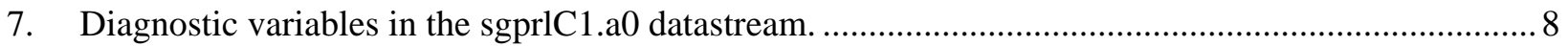

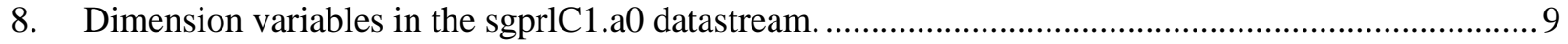

9. Dimension variables in the sgprlprofmerge1turnC1 data stream, i.e. the merge data stream. The height dimensions are currently given by high_bins $=2800$ for the NFOV channels, and

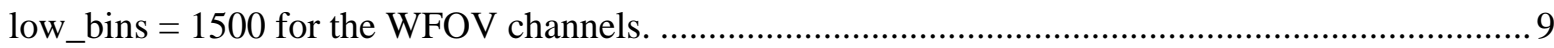

10. Dimension variables in the sgp10rlprofasr1ferrC1, sgp10rlprofmr1turnC1 and

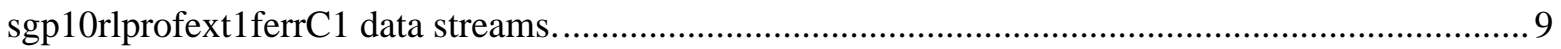

11. Primary data products generated by each of the RL VAPs............................................................. 16

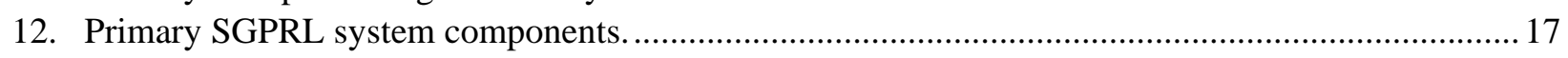

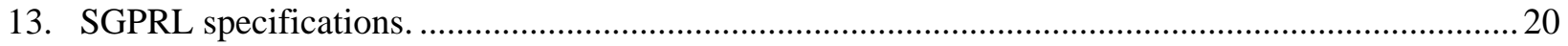




\section{General Overview}

The Raman lidar at the ARM Climate Research Facility (ACRF) Southern Great Plains (SGP) Central Facility (SGPRL) is an active, ground-based laser remote sensing instrument that measures height and time resolved profiles of water vapor mixing ratio and several cloud- and aerosol-related quantities. The system is a non-commercial custom-built instrument developed by Sandia National Laboratories specifically for the ARM Program. It is fully computer automated, and will run unattended for many days following a brief ( $\sim 5$-minute) startup period. The self-contained system (requiring only external electrical power) is housed in a climate-controlled 8'x8'x20' standard shipping container.

\section{Contacts}

\subsection{Mentor}

Rob Newsom

Pacific Northwest National Laboratory

P.O. Box 999, MSIN K9-30

Richland, WA 99352

Phone: 509-372-6020

Fax: 509-372-6168

rob.newsom@pnl.gov

Dave Turner (Associate)

University of Wisconsin - Madison

dturner@ssec.wisc.edu

John Goldsmith (engineering)

Sandia National Laboratories

Phone: 925-294-2432

jgold@sandia.gov

\subsection{Instrument Developer}

John Goldsmith

Sandia National Laboratories

P.O. Box 969, MS 9409

Livermore, CA 94551-0969

Phone: 925-294-2432

jgold@sandia.gov

\section{Deployment Locations and History}

In the early 1990s ARM funded a collaboration between Sandia National Laboratories and the NASA Goddard Space Flight Center to pursue technology improvements that would meet ARM's requirements for ground-based remote sensing of water vapor. The success of that effort led to the decision to build a Raman lidar system, and during the summer of 1996, the system was delivered to the ACRF's SGP Central Facility near Billings, Oklahoma. During its initial shakedown period, the instrument participated in the Water Vapor Intensive Operational Periods (IOPs) in 1996 and 1997 before becoming fully operational in February 1998. 
The original Raman lidar had seven detection channels and utilized photon counting detection electronics. During the first four years of its deployment, the system generally functioned well, and produced the first data set of continuous multi-annual Raman lidar measurements. Also, during this time value-added procedures (VAPs) were developed to generate science data products from the raw photon counting data. These data products include water vapor mixing ratio, relative humidity, aerosol scattering ratio, aerosol backscatter, aerosol extinction, aerosol optical depth, aerosol depolarization ratio, and cloud base height.

In early 2002, the sensitivity of SGPRL began degrading. This loss of sensitivity, which affected all observed variables, was very gradual and thus was not identified until the autumn of 2003. Analysis of the data indicated that the problem was in the detection subsystem. In an attempt to restore the lidar's sensitivity back to its nominal level, the system underwent a major refurbishment in 2004.

During the 2004 refurbishment, a variety of optical components were replaced in a systematic manner in order to evaluate the impact of each replacement. Replacing the interference filters and resurfacing the mirrors of the primary telescope resulted in the greatest improvement in the sensitivity and restored its performance to the level it had in 1998. Also, during the course of the 2004 refurbishment, the existing photon counting electronics were replaced with new Licel transient data recorders. The Licel data recorders provide simultaneous measurements of analog photomultiplier voltage and photon counts, whereas the orginal data system provided only photon counting measurements. The combined use of photon counting and analog data resulted in a dramatic improvement in the dynamic range of all detection channels. The new Licel data recorders also enabled a significant improvement in the vertical resolution of the measurements (from $39 \mathrm{~m}$ to $7.5 \mathrm{~m}$ ).

Two more upgrades were performed in October 2005 and April 2007. In October 2005, three new detection channels were added to enable profiling of temperature and liquid water content. In April 2007, a new boresight alignment system was added. The boresight alignment system continually adjusts the alignment of the outgoing transmit beam to maximize the return power, thus maintaining the alignment of the outgoing beam with the optical axis of the telescope. The installation of this device eliminated the need for periodic "alignment tweaks," and has resulted in an overall improvement in the data quality.

Figure 1 shows uptime for SGPRL from 1996 to 2009. The average uptime during this entire period was $\sim 67 \%$. The average uptime just after completion of the major refurbishment (October 2004) to the beginning of 2009 was $\sim 89 \%$. Figure 1 also shows the times of significant instrument upgrades and milestones. 


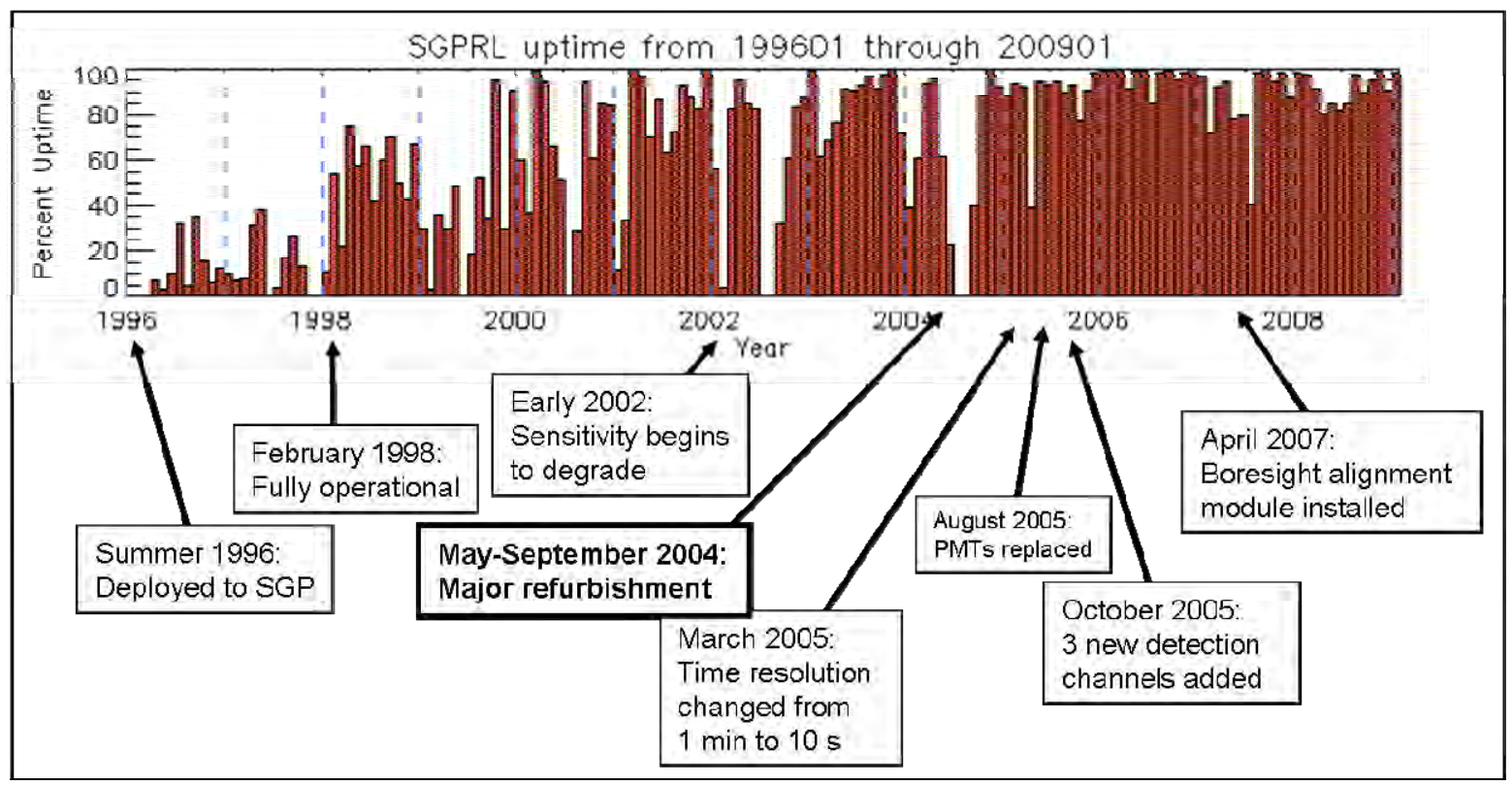

Figure 1. SGPRL Uptime from 1998 to 2009 and significant system upgrade and milestones.

\section{Near-Real-Time Data Plots}

Raw signals acquired by the SGPRL can be viewed in near-real-time by accessing the web site NCVweb. This site provides an interactive web-based tool for plotting various ARM datastreams that are received and stored at the ACRF Data Management Facility (DMF). To view raw data from the SGPRL select the SGP site and then select the sgprlC1.a0 data stream. A listing of all raw data files stored currently at the DMF will then appear. This typically includes the most recent 3 to 5 months of data. Select the most recent file to view data in near-real-time.

Each sgprlC1.a0 netCDF file covers a 12-hour period, i.e., 0 to 12 and 12 to 24 UTC. The most recent file in the list is typically in the process of being updated. Currently, raw RL data packets are transmitted from SGP to the DMF at 15-minute intervals. These packets are then formatted and appended to the most recent sgprlC1.a0 netCDF file. At the end of the current 12-hour cycle that file is closed and a new sgprlC1.a0 netCDF file is opened for writing.

A single sgprlC1.a0 netCDF file contains a large amount of information (each file is about $1 \mathrm{~Gb}$ in size). These files include engineering and diagnostic information as well as profiles of raw return signals from 10 detection channels (7 channels prior to October 27, 2005). With the addition of the Licel transient data recorder each channel generates profiles of both PMT analog voltage output and photon counts at a time and height resolution of 10 seconds and $7.5 \mathrm{~m}$, respectively. Thus, each sgprlC1.a0 netCDF file contains 20 two-dimensional arrays of lidar return data, in addition to a number of one-dimensional arrays and scalar variables that store information such as laser pulse energy, filter mode, air temperature, and relative humidity inside the lidar container. A more detailed description of the sgprlC1.a0 data stream is provided in Section 5.1.

The various science data products (e.g., aerosol extinction, water vapor mixing ratio, depolarization ratio, etc...) that are generated by the SGPRL VAPs currently are not being computed in the near-real-time. 
Generation of these data products require careful monitoring by the mentor to ensure that various corrections are updated properly. As result, near-real-time plots of the various water vapor and aerosol data products are not available. The latency on these data products is typically anywhere from 1 week to 1 month.

\section{Data Description and Examples}

SGPRL data are available from the ACRF Data Archive in the following data streams: sgprlC1.a0, sgprlprofmerge1turnC1, sgp10rlprofasr1ferrC1, sgp10rlprofext1ferrC1, sgp10rlprofmr1turnC1, and sgp10rlprofdep1turnC1.

\subsection{Data File Contents}

\subsubsection{Primary Variables and Expected Uncertainty}

Tables 1 through 5 list the primary quantities associated with each of the SGPRL data streams.

Table 1. Primary variables in the sgprlC1.a0 datastream. See Table 8 for a description of dimensions.

\begin{tabular}{|c|c|c|c|c|}
\hline Variable & Dimensions & Channel Name & $\lambda(\mathbf{n m})$ & Description \\
\hline Water_counts_high & time $\mathrm{x}$ high_bins & Water_high & 408 & $\begin{array}{l}\text { Photo-counts in the NFOV water vapor } \\
\text { channel }\end{array}$ \\
\hline Water_analog_high & time $\mathrm{x}$ high_bins & Water_high & 408 & $\begin{array}{l}\text { Analog signal in the NFOV water vapor } \\
\text { channel }\end{array}$ \\
\hline nitrogen_counts_high & time $\mathrm{x}$ high_bins & Nitrogen_high & 387 & Photo-counts in NFOV nitrogen channel \\
\hline nitrogen_analog_high & time $\mathrm{x}$ high_bins & Nitrogen_high & 387 & Analog signal in the NFOV nitrogen channel \\
\hline Elastic_counts_high & time $\mathrm{x}$ high_bins & Elastic_high & 355 & $\begin{array}{l}\text { Photo-counts in NFOV elastic channel } \\
\text { (parallel polarization to the laser) }\end{array}$ \\
\hline Elastic_analog_high & time $\mathrm{x}$ high_bins & Elastic_high & 355 & Analog signal in the NFOV elastic channel \\
\hline $\begin{array}{l}\text { depolarization_counts } \\
\text { _high }\end{array}$ & time $\mathrm{x}$ high_bins & Depolarization_high & 355 & $\begin{array}{l}\text { Photo-counts in NFOV depolarization channel } \\
\text { (perpendicular polarization to the laser) }\end{array}$ \\
\hline $\begin{array}{l}\text { depolarization_analog } \\
\text { _high }\end{array}$ & time $\mathrm{x}$ high_bins & Depolarization_high & 355 & $\begin{array}{l}\text { Analog signal in the NFOV depolarization } \\
\text { channel }\end{array}$ \\
\hline t1_counts_high & time $\mathrm{x}$ high_bins & T1_high & 353 & Photo-counts in NFOV temperature 1 channel \\
\hline t1_analog_high & time $\mathrm{x}$ high_bins & T1_high & 353 & Analog signal in the temperature 1 channel \\
\hline t2_counts_high & time $\mathrm{x}$ high_bins & T2_high & 354 & Photo-counts in NFOV temperature 2 channel \\
\hline t2_analog_high & time $\mathrm{x}$ high_bins & T2_high & 354 & Analog signal in the temperature 2 channel \\
\hline Liquid_counts_high & time $\mathrm{x}$ high_bins & Liquid_high & $?$ & Photo-counts in NFOV liquid water channel \\
\hline Liquid_analog_high & time $\mathrm{x}$ high_bins & Liquid_high & ? & Analog signal in the liquid water channel \\
\hline Water_counts_low & time $\mathrm{x}$ low_bins & Water_low & 408 & Photo-counts in WFOV water vapor channel \\
\hline Water_analog_low & time $\mathrm{x}$ low_bins & Water_low & 408 & $\begin{array}{l}\text { Analog signal in the WFOV water vapor } \\
\text { channel }\end{array}$ \\
\hline nitrogen_counts_low & time $\mathrm{x}$ low_bins & Nitrogen_low & 387 & Photo-counts in WFOV nitrogen channel \\
\hline nitrogen_analog_low & time $\mathrm{x}$ low_bins & Nitrogen_low & 387 & Analog signal in the WFOV nitrogen channel \\
\hline Elastic_counts_low & time $\mathrm{x}$ low_bins & Elastic_low & 355 & $\begin{array}{l}\text { Photo-counts in WFOV elastic (aerosol) } \\
\text { channel }\end{array}$ \\
\hline Elastic_analog_low & time $\mathrm{x}$ low_bins & Elastic_low & 355 & Analog signal in the WFOV elastic channel \\
\hline
\end{tabular}


Table 2. Primary variables in the sgprlprofmerge1turnC1 datastream. See Table 9 for a description of dimensions.

\begin{tabular}{|c|c|c|c|c|}
\hline Variable & Dimensions & Channel Name & $\lambda(\mathrm{nm})$ & Description \\
\hline Water_counts_high & $\begin{array}{l}\text { time } x \\
\text { high_bins }\end{array}$ & Water_high & 408 & $\begin{array}{l}\text { Photon count rate in the NFOV } \\
\text { water vapor channel (MHz) }\end{array}$ \\
\hline nitrogen_counts_high & $\begin{array}{l}\text { time } x \\
\text { high_bins }\end{array}$ & Nitrogen_high & 387 & $\begin{array}{l}\text { Photon count rate in NFOV } \\
\text { nitrogen channel (MHz) }\end{array}$ \\
\hline Elastic_counts_high & $\begin{array}{l}\text { time } x \\
\text { high_bins }\end{array}$ & Elastic_high & 355 & $\begin{array}{l}\text { Photon count rate in NFOV elastic } \\
\text { channel. This channel measures } \\
\text { polarization parallel to the laser } \\
(\mathrm{MHz}) \text {. }\end{array}$ \\
\hline depolarization_counts_high & $\begin{array}{l}\text { time } x \\
\text { high_bins }\end{array}$ & Depolarization_high & 355 & $\begin{array}{l}\text { Photon count rate in NFOV } \\
\text { depolarization channel. This } \\
\text { channel measures the polarization } \\
\text { perpendicular to the laser. (MHz) }\end{array}$ \\
\hline t1_counts_high & $\begin{array}{l}\text { time } x \\
\text { high_bins }\end{array}$ & T1_high & 353 & $\begin{array}{l}\text { Photon count rate in NFOV } \\
\text { temperature } 1 \text { channel }(\mathrm{MHz})\end{array}$ \\
\hline t2_counts_high & $\begin{array}{l}\text { time } x \\
\text { high_bins }\end{array}$ & T2_high & 354 & $\begin{array}{l}\text { Photon count rate in NFOV } \\
\text { temperature } 2 \text { channel (MHz) }\end{array}$ \\
\hline Liquid_counts_high & $\begin{array}{l}\text { time } x \\
\text { high_bins }\end{array}$ & Liquid_high & $?$ & $\begin{array}{l}\text { Photon count rate in NFOV liquid } \\
\text { water channel }(\mathrm{MHz})\end{array}$ \\
\hline Water_counts_low & $\begin{array}{l}\text { time } x \\
\text { low_bins }\end{array}$ & Water_low & 408 & $\begin{array}{l}\text { Photon count rate in WFOV water } \\
\text { vapor channel }(\mathrm{MHz})\end{array}$ \\
\hline nitrogen_counts_low & $\begin{array}{l}\text { time } x \\
\text { low_bins }\end{array}$ & Nitrogen_low & 387 & $\begin{array}{l}\text { Photon count rate in WFOV } \\
\text { nitrogen channel }(\mathrm{MHz})\end{array}$ \\
\hline Elastic_counts_low & $\begin{array}{l}\text { time } x \\
\text { low_bins }\end{array}$ & Elastic_low & 355 & $\begin{array}{l}\text { Photon count rate in WFOV elastic } \\
\text { channel (MHz) }\end{array}$ \\
\hline Cbh & time & - & 355 & $\begin{array}{l}\text { Cloud base height in km as } \\
\text { determined from the elastic_low } \\
\text { channel }\end{array}$ \\
\hline
\end{tabular}

Table 3. Primary variables in the sgp10rlprofasr1ferrC1 datastream. See Table 10 for a description of dimensions.

\begin{tabular}{|l|l|l|l|}
\hline \multicolumn{1}{|c|}{ Variable } & \multicolumn{1}{c|}{ Dimensions } & \multicolumn{1}{c|}{ Units } & \multicolumn{1}{c|}{ Description } \\
\hline cal_asr_1 & $\begin{array}{l}\text { Time } \mathrm{x} \\
\text { height_high }\end{array}$ & unitless & $\begin{array}{l}\text { Aerosol scattering ratio profile created by merging } \\
\text { the two Calibrated channels }\end{array}$ \\
\hline cal_asr_1_error & $\begin{array}{l}\text { Time } \mathrm{x} \\
\text { height_high }\end{array}$ & unitless & $\begin{array}{l}\text { Uncertainty of the aerosol scattering ratio profile } \\
\text { created by merging the two Calibrated channels }\end{array}$ \\
\hline Backscatter & $\begin{array}{l}\text { Time } \mathrm{x} \\
\text { height_high }\end{array}$ & $1 /(\mathrm{km}$-ster) & $\begin{array}{l}\text { Aerosol volume backscattering coefficient at } \\
355 \mathrm{~nm}\end{array}$ \\
\hline bscat_err & $\begin{array}{l}\text { time, } \mathrm{x} \\
\text { height_high }\end{array}$ & $1 /(\mathrm{km}$-ster) $)$ & $\begin{array}{l}\text { Error in Aerosol volume backscattering coefficient } \\
\text { at 355 } \mathrm{nm}\end{array}$ \\
\hline
\end{tabular}


Table 4. Primary variables in the sgp10rlprofext1ferrC1 datastream. See Table 10 for a description of dimensions.

\begin{tabular}{|l|l|l|l|}
\hline \multicolumn{1}{|c|}{ Variable } & \multicolumn{1}{|c|}{ Dimensions } & \multicolumn{1}{|c|}{ Units } & \multicolumn{1}{c|}{ Description } \\
\hline extinction_from_backscatter & $\begin{array}{l}\text { Time } \mathrm{x} \\
\text { height_high }\end{array}$ & $\mathrm{Km}^{\wedge}(-1)$ & $\begin{array}{l}\text { Aerosol extinction coefficient profile calculated } \\
\text { from backscatter and the extinction-to- } \\
\text { backscatter ratio }\end{array}$ \\
\hline extinction_from_backscatter_error & $\begin{array}{l}\text { Time } \mathrm{x} \\
\text { height_high }\end{array}$ & $\mathrm{Km}^{\wedge}(-1)$ & $\begin{array}{l}\text { Uncertainty of the aerosol extinction coefficient } \\
\text { profile calculated from the aerosol backscatter } \\
\text { coefficient }\end{array}$ \\
\hline aod_bscat & Time & Unitless & $\begin{array}{l}\text { Aerosol optical depth calculated from the } \\
\text { extinction_from_backscatter profile }\end{array}$ \\
\hline aod_bscat_error & time & unitless & $\begin{array}{l}\text { Uncertainty of the aerosol extinction coefficient } \\
\text { profile calculated from the aerosol backscatter } \\
\text { coefficient }\end{array}$ \\
\hline
\end{tabular}

Table 5. Primary variables in the sgp10rlprofmr1turnC1 datastream. See Table 10 for definition of dimensions.

\begin{tabular}{|l|l|l|l|}
\hline \multicolumn{1}{|c|}{ Variable } & Dimensions & Units & \multicolumn{1}{c|}{ Description } \\
\hline mixing_ratio_3 & $\begin{array}{l}\text { Time } \mathrm{x} \\
\text { height }\end{array}$ & $\mathrm{g} / \mathrm{kg}$ & $\begin{array}{l}\text { Water vapor mixing ratio profile created by merging the two } \\
\text { calibrated channels together with the surface in situ } \\
\text { measurements }\end{array}$ \\
\hline relative_humidity & $\begin{array}{l}\text { Time } \mathrm{x} \\
\text { height }\end{array}$ & $\%$ & $\begin{array}{l}\text { Relative humidity calculated from the merged water vapor } \\
\text { mixing ratio data }\end{array}$ \\
\hline mixing_ratio_3_error & $\begin{array}{l}\text { Time } \mathrm{x} \\
\text { height }\end{array}$ & $\mathrm{g} / \mathrm{kg}$ & $\begin{array}{l}\text { Uncertainty of the water vapor mixing ratio profile created by } \\
\text { merging the two calibrated channels }\end{array}$ \\
\hline pwv_rl(time) & Time & Cm & Precipitable water vapor observed by the Raman lidar \\
\hline pwv_rl_err(time) & Time & Cm & $\begin{array}{l}\text { Random error in the precipitable water vapor observed by the } \\
\text { Raman lidar }\end{array}$ \\
\hline
\end{tabular}

Biases in the lidar derived water vapor mixing ratios have been evaluated by comparing with simultaneous and collocated radiosonde measurements. During a recent study the lidar-to-sonde comparisons were conducted over a six-month period from 1 April to 30 September, 2007. Figure 2 shows profiles of the mean normalized difference between the sonde and lidar water vapor mixing ratio for daytime and nighttime operation. The differences are normalized by the sonde mixing ratios, and positive values imply a wet bias of the lidar relative to the sonde. Daytime and nighttime profiles were averaged separately based on the count rate of the solar background in the wide FOV water vapor channel (water_low). Daytime periods were defined as having a solar background level greater than $1 \mathrm{MHz}$, and nighttime periods were defined as having a solar background less than $0.01 \mathrm{MHz}$. Only soundings during cloud-free periods were used in the comparisons. This resulted in 140 daytime and 120 nighttime soundings during the period from 1 April to 30 September 2007.

As shown in Figure 2, the mean biases remain less than $4 \%$ for $\mathrm{z}<5 \mathrm{~km}$ during the nighttime, and less than $5 \%$ for $\mathrm{z}<4 \mathrm{~km}$ during the daytime. The standard deviation of the distribution, as indicated by the shaded area, increases with height and is clearly smaller at night than during the day, as expected. For 
nighttime operation the standard deviation at 5-km AGL is approximately $10 \%$; whereas, during the daytime a standard deviation of $10 \%$ occurs slightly above 3-km AGL. When averaged vertically from 0 to $5-\mathrm{km}$ AGL, the mean biases are found to be less than or approximately equal to $1 \%$ for both day and night operation.

(a) Nighttime

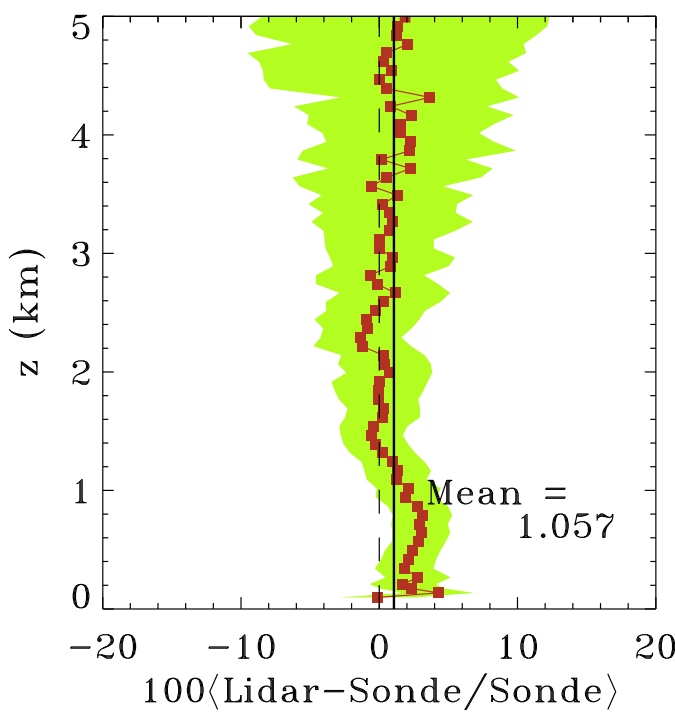

(b) Daytime

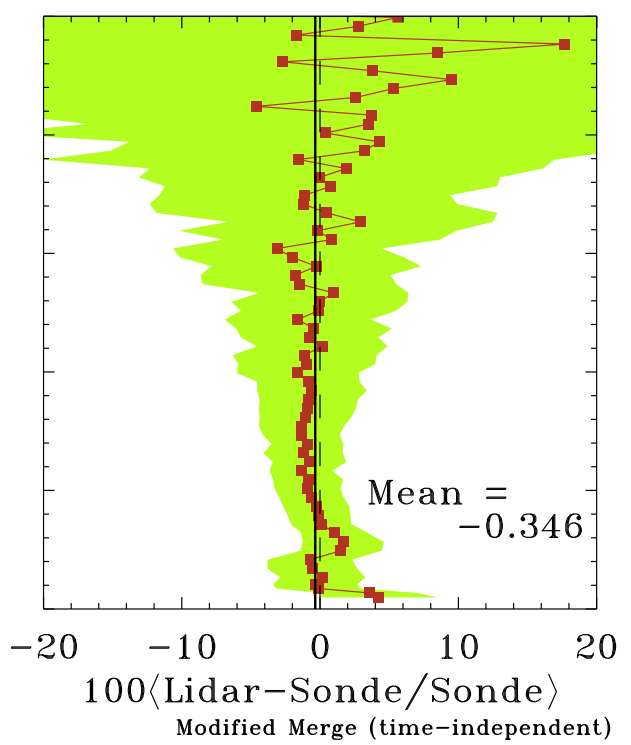

Figure 2. Profiles of mean normalized bias in the $R L$ relative to the radiosonde water vapor mixing ratio measurements for (a) nighttime and (b) daytime soundings. The solid lines indicate the value of the vertically averaged lidar-to-sonde ratio over the displayed height range, and the dotted line indicates zero bias. These results are based on 140 daytime soundings and 120 nighttime soundings between 1 April and 30 September 2007.

\subsubsection{Definition of Uncertainty}

All raw signals are either photon counts or PMT analog voltages for a specified averaging interval (in time and range). Poisson statistics are used to calculate statistical uncertainties for all derived quantities.

\subsubsection{Secondary/Underlying Variables}

Each VAP generates or uses a variety of secondary variables. Secondary variables associated with the sgprlC1.a0 datastream are listed in Table 6. These variables are passed with no modification into the sgprlprofmerge1turnC1 data stream. In addition to these variables, there are a large number of new variables generated by the rlprofmerge VAP that store parameters used in the process of "gluing" the raw analog and photon counting data. 
Table 6. Secondary variables in the sgprlC1.a0 datastream. All of these secondary variables have dimensions of time. The time dimension is unlimited, but is generally about 8000 for a 12-hour period.

\begin{tabular}{|c|c|}
\hline Variable & Description \\
\hline shots_summed_water_high & Number of laser shots accumulated for the water_high channel \\
\hline shots_summed_nitrogen_high & Number of laser shots accumulated for the nitrogen_high channel \\
\hline shots_summed_elastic_high & Number of laser shots accumulated for the elastic_high channel \\
\hline shots_summed_depolarization_high & Number of laser shots accumulated for the depolarization_high channel \\
\hline shots_summed_t1_high & Number of laser shots accumulated for the T1_high channel \\
\hline shots_summed_t2_high & Number of laser shots accumulated for the T2_high channel \\
\hline shots_summed_liquid_high & Number of laser shots accumulated for the LW_high channel \\
\hline shots_summed_water_low & Number of laser shots accumulated for the water_low channel \\
\hline shots_summed_nitrogen_low & Number of laser shots accumulated for the nitrogen_low channel \\
\hline shots_summed_elastic_low & Number of laser shots accumulated for the elastic_low channel \\
\hline pulse_energy & Laser pulse energy in $\mathrm{mJ}$ \\
\hline Filter & $\begin{array}{l}\text { Flag indicating the filters currently in use. } \\
\text { - Value of } 0 \text { implies the filter wheels are closed } \\
\text { - Value of } 1 \text { implies that the common filter wheels are open and the LW } \\
\text { channel has filter \# } 1 \text { in place } \\
\text { - Value of } 2 \text { implies that the common filter wheels are open and the LW } \\
\text { channel has filter \#2 in place }\end{array}$ \\
\hline $\mathrm{Rh}$ & Relative humidity inside the instrument enclosure (\%) \\
\hline temp1 to temp6 & $\begin{array}{l}\text { Air temperatures measured at various locations inside the instrument } \\
\text { enclosure }\left({ }^{\circ} \mathrm{C}\right)\end{array}$ \\
\hline
\end{tabular}

\subsubsection{Diagnostic Variables}

Table 7. Diagnostic variables in the sgprlC1.a0 datastream. All of these se variables have dimensions of time.

\begin{tabular}{|c|c|}
\hline Variable & Description \\
\hline n2_cloud_check_value & $\begin{array}{l}\text { The sum of the nitrogen_high photon counting signal from 1.9-2.4 km normalized by the } \\
\text { number of shots and the pulse energy. }\end{array}$ \\
\hline cloud_value_check & $\begin{array}{ll}\text { A flag indicating cloudiness } \\
\text { - Value of } 0 \text { indicates not cloudy } \\
\text { - Value of } 1 \text { is given if cloudy based on attenuation of N2 signal only } \\
\text { - Value of } 2 \text { is given if cloudy based on a large gradient in the low elastic } \\
\end{array}$ \\
\hline laser_head & $\begin{array}{ll}\text { Laser head in use } \\
\text { - } \quad \text { Value of } 0 \text { indicates old laser head in use } \\
\text { - } \quad \text { Value of } 1 \text { indicates new laser head in use }\end{array}$ \\
\hline $\mathrm{s} 1-\mathrm{s} 10$ & These variables store various system diagnostic information \\
\hline
\end{tabular}




\subsubsection{Data Quality Flags}

See RL Data Object Design Changes for ARM netCDF file header descriptions.

\subsubsection{Dimension Variables}

Table 8. Dimension variables in the sgprlC1.a0 datastream. The height dimensions are given currently by high_bins $=4000$ for the NFOV (high) channels, and low_bins $=1500$ for the WFOV (low) channels. The time dimension is unlimited, but generally runs about 4000 for a 12-hour period.

\begin{tabular}{|l|l|l|}
\hline Variable & Dimensions & \multicolumn{1}{c|}{ Description } \\
\hline Base_time & Scalar & Start time in seconds since 1970-1-1 0:00:00 0:00 \\
\hline Time_offset & Time & Time offset from base_time in seconds \\
\hline High_bins & Scalar & Number height bins for the NFOV (high) channels \\
\hline Low_bins & Scalar & Number height bins for the WFOV (low) channels \\
\hline Lat & Scalar & Latitude of site in degrees North \\
\hline Lon & Scalar & Longitude of site in degrees East \\
\hline Alt & Scalar & Altitude of site in meters above sea level \\
\hline
\end{tabular}

Table 9. Dimension variables in the sgprlprofmerge1turnC1 datastream, i.e., the merge datastream. The height dimensions are given currently by high_bins $=2800$ for the NFOV (high) channels, and low_bins $=1500$ for the WFOV (low) channels. The time dimension is unlimited, but generally runs about 8000 for a 24-hour period.

\begin{tabular}{|l|l|l|}
\hline Variable & Dimensions & \multicolumn{1}{c|}{ Description } \\
\hline Base_time & Scalar & Start time in seconds since 1970-1-1 0:00:00 0:00 \\
\hline Time_offset & Time & Time offset from base_time in seconds \\
\hline Height_high & High_bins & Height array for NFOV (high) channels in km AGL \\
\hline Height_low & Low_bins & Height array for WFOV (low) channels in km AGL \\
\hline Lat & Scalar & Latitude of site in degrees North \\
\hline Lon & Scalar & Longitude of site in degrees East \\
\hline Alt & Scalar & Altitude of site in meters above sea level \\
\hline
\end{tabular}

Table 10. Dimension variables in the sgp10rlprofasr1ferrC1, sgp10rlprofmr1turnC1 and sgp10rlprofext1ferrC1 datastreams. Note that the height grid is in general not uniformly spaced. Also, the time dimensions are typically smaller for these datastreams than for either sgprlC1.a0 or sgprlprofmerge1turnC1.

\begin{tabular}{|l|l|l|}
\hline \multicolumn{1}{|c|}{ Variable } & Dimensions & \multicolumn{1}{c|}{ Description } \\
\hline Base_time & Scalar & Start time in seconds since 1970-1-1 0:00:00 0:00 \\
\hline Time_offset & Time & Time offset from base_time in seconds \\
\hline Height_high & Height_high & $\begin{array}{l}\text { Height array for data products formed from the NFOV } \\
\text { (high) channels in km AGL }\end{array}$ \\
\hline Height & Height & $\begin{array}{l}\text { Height array for the primary water vapor mixing ratio and } \\
\text { relative humidity data products (km AGL) }\end{array}$ \\
\hline lat & Scalar & Latitude of site in degrees North \\
\hline Lon & Scalar & Longitude of site in degrees East \\
\hline Alt & Scalar & Altitude of site in meters above sea level \\
\hline
\end{tabular}




\subsection{Annotated Examples}

\subsubsection{Photon Count Rate (Sgprlprofmerge1turnC1)}

Figure 3 through Figure 5 display typical time-height cross sections of photon count rates for several detection channels. These data represent output from the so-called MERGE VAP. After the addition of the Licel recorders in 2004, the MERGE VAP became the first step in the data processing chain for SGPRL. Its main purpose is to optimally combine the raw analog and photon counting signals from the Licel electronics into a single signal that can be ingested by the other Raman lidar VAPs. The output of the MERGE VAP is given in terms of photon count rate, i.e., the number of received photons per unit time within a given range bin.

All of the detection channels display at least one common feature. As the laser pulse propagates through the atmosphere, the return signal initially increases due to incomplete overlap between the receiver fieldof-view (FOV) and the outgoing beam cross section. At some point, attenuation of the beam begins to dominate and the return signal starts to decrease with range. Under non-cloudy conditions, the range at which the signal reaches its maximum is largely determined by the FOV. For SGPRL, this maximum is reached at a range of $\sim 250 \mathrm{~m}$ for the wide FOV (WFOV), and about $1.2 \mathrm{~km}$ for the narrow FOV (NFOV), as indicated in Figure 3. Additionally, complete overlap between the FOV and the outgoing beam is achieved at a range of $\sim 800 \mathrm{~m}$ for the WFOV and $\sim 4 \mathrm{~km}$ for the NFOV.

Figure 3 illustrates typical characteristics of the photon count rate signal for the WFOV and FOV elastic channels $(355 \mathrm{~nm})$. The elastic channels are sensitive to scattering from aerosol and molecular Rayleigh scattering. Clouds typically produce strong elastic returns, as illustrated in Figure 3. As the beam propagates through the cloud, it is strongly attenuated and this often results in a shadowing effect above the cloud. We note that the elastic channels operate at $355 \mathrm{~nm}$, which is in a so-called solar blind region of the spectrum due to absorption of solar radiation by ozone in the stratosphere. As a result, the elastic channels are essentially unaffected to solar radiation.

Figure 4 illustrates typical characteristics of the photon count rate signal for the WFOV and NFOV nitrogen channels (387 nm). The energy sensed in this channel is due to Raman (inelastic) scattering from diatomic nitrogen molecules and solar radiation. Although this channel is not sensitive to aerosol backscatter, it is affected by aerosol extinction. A comparison between Figure 4 and Figure 3 shows that the nitrogen signal does not exhibit a strong return from the cloud base; however, the signal is strongly attenuated inside the cloud. Thus, the nitrogen signal can exhibit the same type of shadowing effect that is characteristic of the elastic return. Figure 4 also illustrates that the nitrogen signal is sensitive to solar radiation. This is evident particularly in the WFOV (Figure 4b).

Figure 5 illustrates typical characteristics of the photon count rate signal for the WFOV and NFOV water vapor channels (408 nm). The energy sensed in this channel is due to Raman (inelastic) scattering from $\mathrm{H}_{2} \mathrm{O}$ molecules and solar radiation. A striking feature of Figure 5 is how the solar background dominates the diurnal variation in these channels. Indeed, the contribution from $\mathrm{H}_{2} \mathrm{O}$ Raman scattering is typically fairly weak (usually less than $10 \mathrm{MHz}$ of dynamic range). Despite this, the instrument is able to measure profiles of water vapor mixing ratio with a high degree of accuracy. 

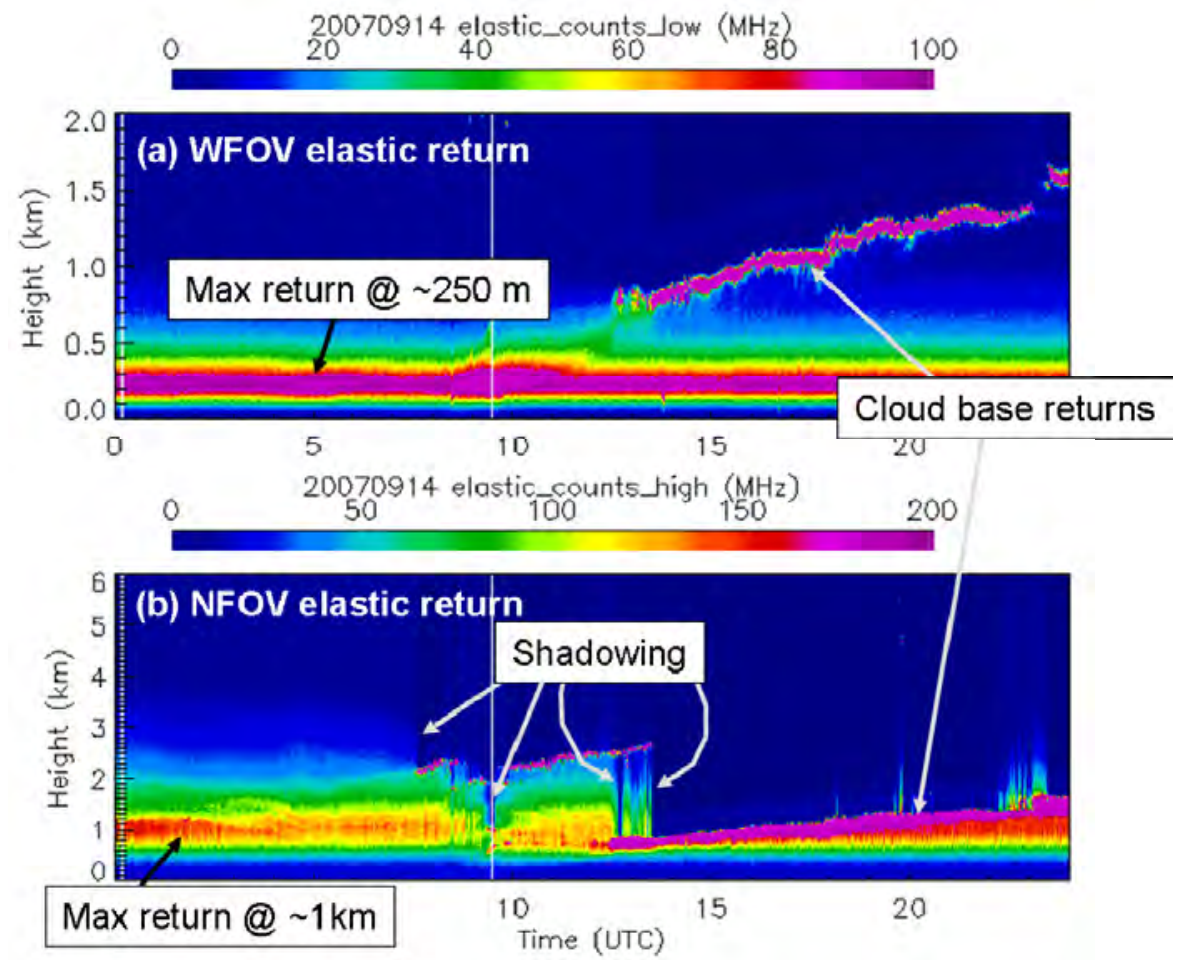

Figure 3. Time-height cross sections of photon count rates from (a) the WFOV elastic channel (355 nm), and (b) the NFOV elastic channel (355 nm), on 14 September 2007.
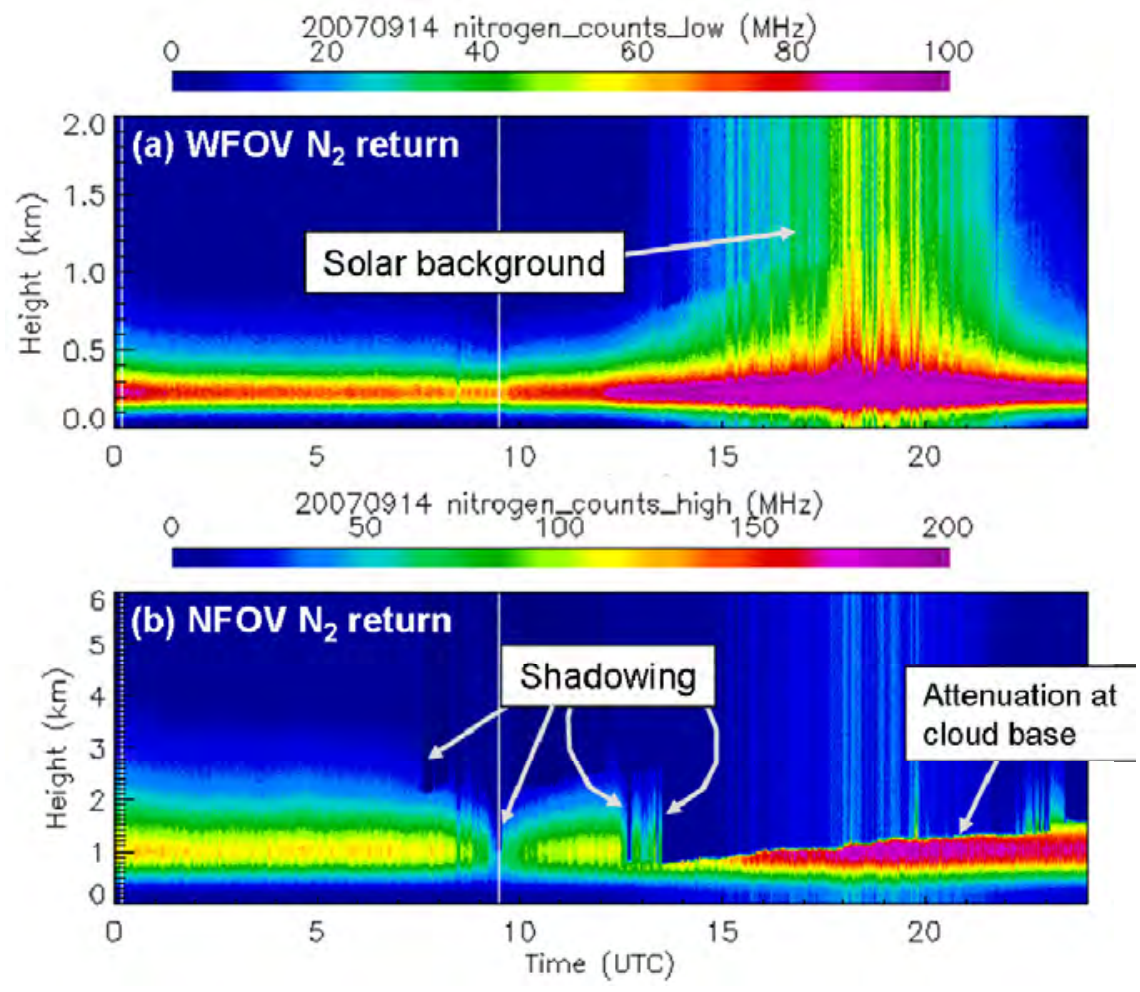

Figure 4. Time-height cross sections of photon count rates from (a) the WFOV nitrogen channel (387 nm), and (b) the NFOV nitrogen channel (387 nm), on 14 September 2007. 

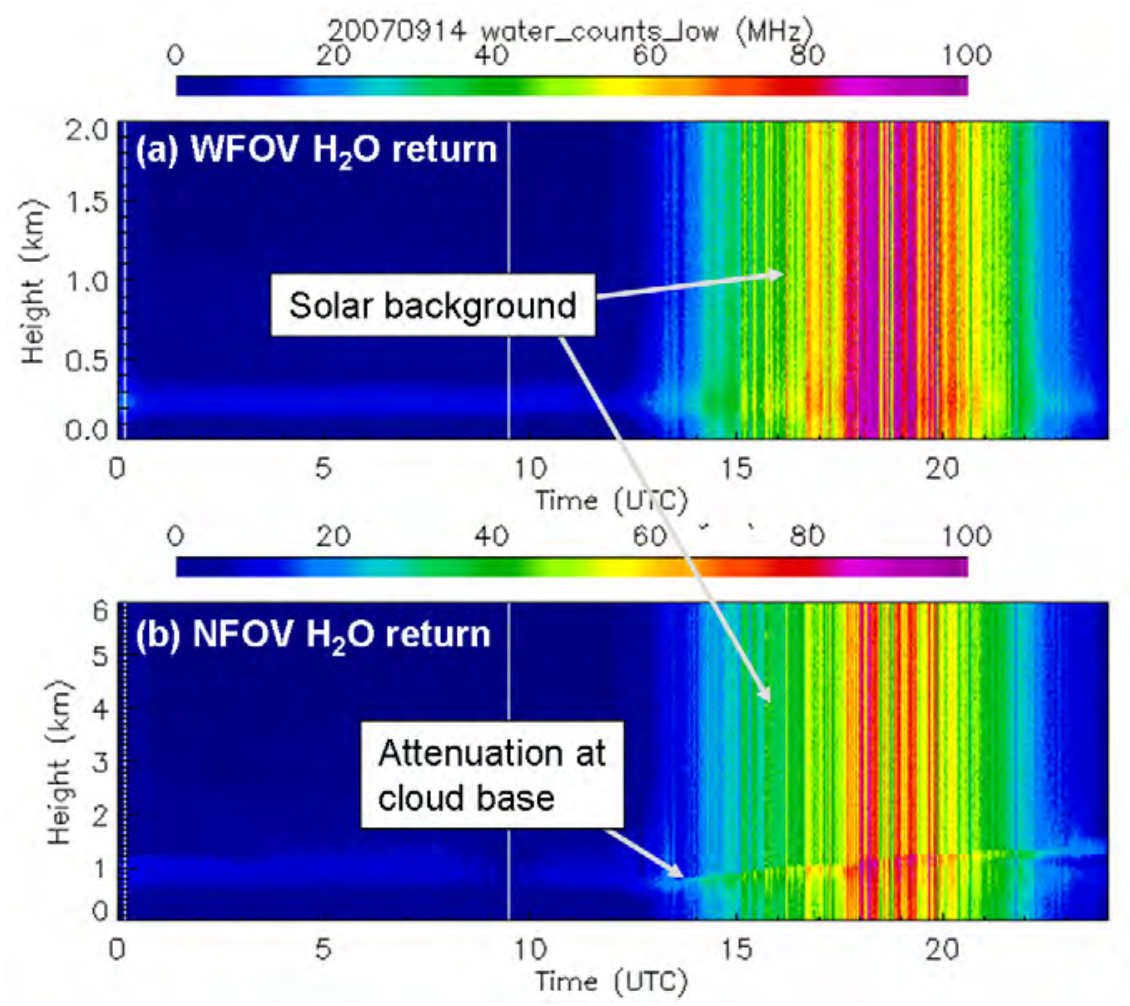

Figure 5. Time-height cross sections of photon count rates from (a) the WFOV water vapor channel $(408 \mathrm{~nm})$, and (b) the NFOV water vapor channel (408 nm), on 14 September 2007.

\subsubsection{Aerosol Scattering Ratio (Sgprlprofasr1ferrC1)}

Figure 6 and Figure 7 show typical examples of aerosol scattering ratio (ASR) and artifacts that may sometimes appear in the final products. Figure 6a shows an example of a reasonably good ten-minute averaged data product for 16 August 2007. Few clouds were present on this particular day. The ASR data show the aerosol structure during the nighttime and the developing convective boundary layer during the daytime. The high ASR value near the top of the convective boundary may be due, at least in part, to hygroscopic swelling of the aerosol. The data become visibly noisier during the daytime due to the effect of the solar background on the nitrogen signal, which is used in the computation of the ASR.

Figure 6b illustrates the effect on the ASR data when no overlap correction is applied. Incomplete overlap between the beam and the FOV can cause a range-dependent distortion of the ASR field below about $2 \mathrm{~km}$. A comparison between Figure 6a and Figure 6b shows that this effect can be quite significant.

The ASR VAP generates its final output by merging ASR fields computed separately from the NFOV and WFOV channels. During this process the VAP attempts to automatically determine an overlap correction for the NFOV ASR field by using the WFOV ASR. Unfortunately, this doesn't always work flawlessly, and artifacts are occasionally introduced. Figure 7 shows a particularly agregious example in which several obvious non-physical discontinuities occur in the time-height cross section due to this limitation in the VAP. 

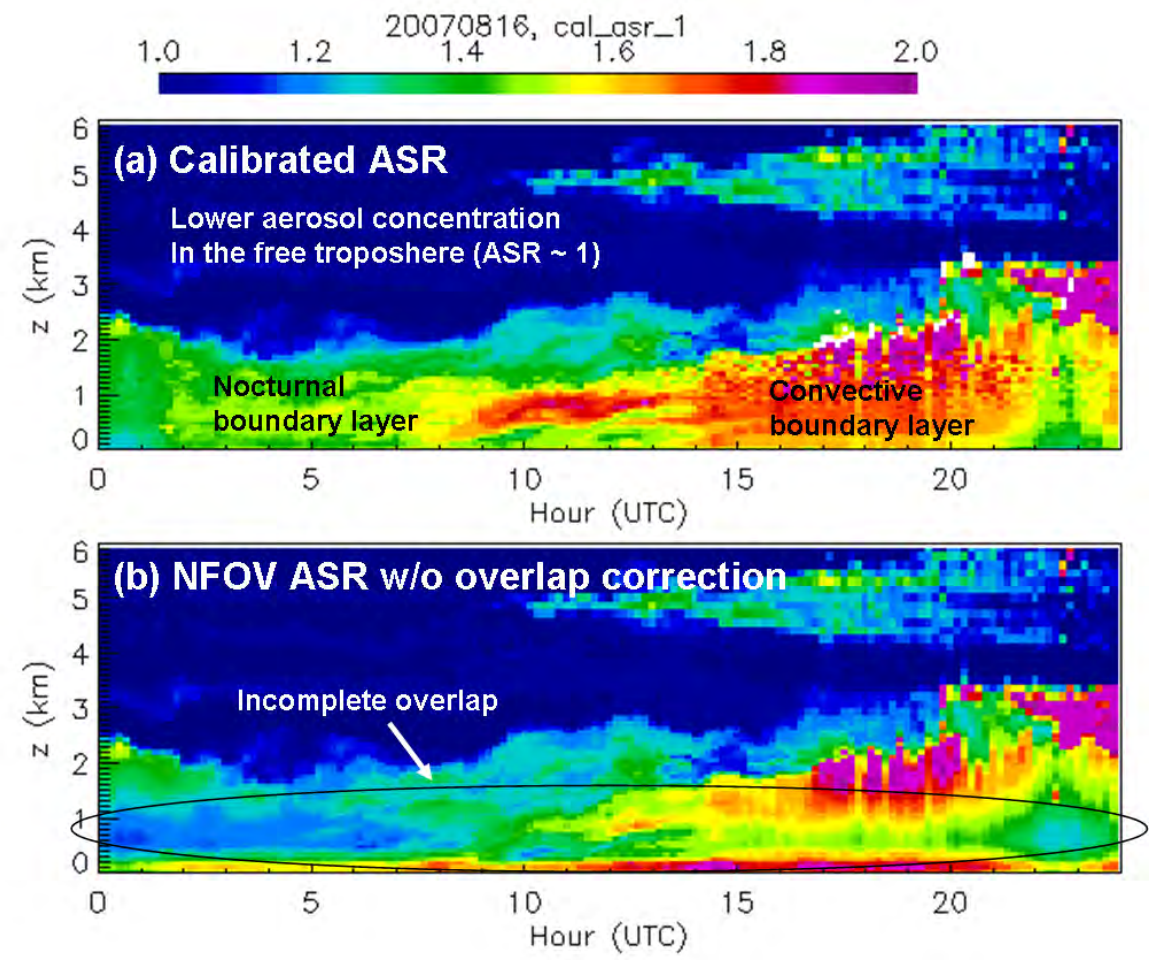

Figure 6. (a) Calibrated ASR data from 16 August 2007, and (b) NFOV ASR data for the same day with no overlap correction applied.

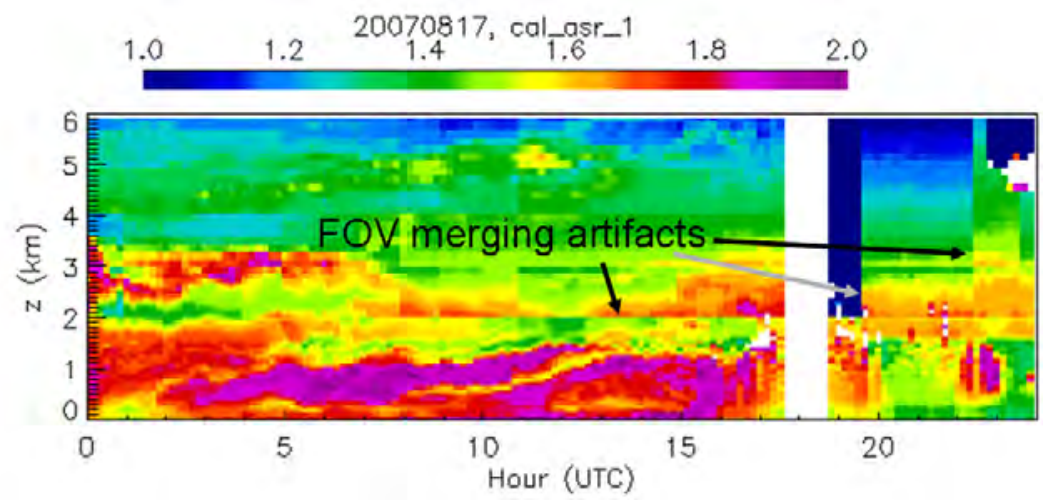

Figure 7. Example showing artifacts in the ASR data due to FOV merging.

\subsubsection{Water Vapor Mixing Ratio (Sgprlprofmr1turnC1)}

Figure 8 displays a four-day-long time-height cross section of water vapor mixing ratio derived from SGPRL measurements. This particular example covers the period from 13 through 16 September, 2007. A relatively shallow tongue of drier air, associated with a cold front, propagated through the site on 14 September (Julian day 257). The time-height cross section in Figure 8 shows clearly the sharp delineation between the dry and moist air, and how the dry air appears to under cut and force the moist air aloft. It is also interesting to note the appearance of waves that precede the cold front at an altitude of between 1 and $2 \mathrm{~km}$ AGL. 
The performance of the Raman lidar system is best during nighttime, in the absence of the daytime solar background. During the daytime solar photons increase the noise in the water vapor field, resulting in a reduction of the maximum range of the measurements. This effect also is clearly visible in Figure 8. During the periods marked "daytime" the measurements become visibly noisier. It is important to note that the data shown in Figure 8 were acquired using the newer detection electronics (Licel transient data recorders). These new electronics have enabled water vapor profiling up to 5-6 km AGL during the day, which is a marked improvement over the original version of this lidar ( $3 \mathrm{~km}$ in 1999).

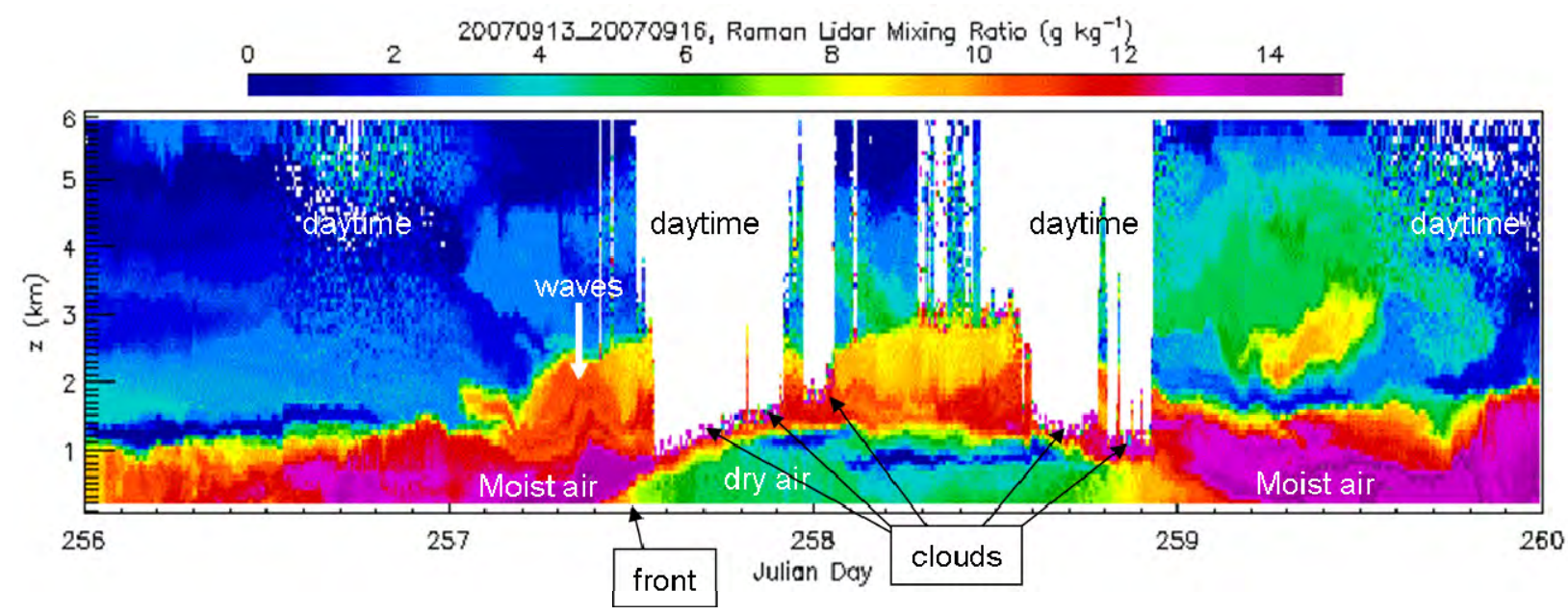

Figure 8. Example of water vapor mixing derived from SGPRL measurements. This shows four days of ten-minute averaged data from 13 September through 16 September, 2007.

\subsection{User Notes and Known Problems}

This section is under development.

\subsection{Frequently Asked Questions}

This section is under development.

\section{Data Quality}

\subsection{Data Quality Health and Status}

The Data Quality Office (DQO) website has links to several tools for inspecting and assessing raw Raman lidar data quality:

- DQ HandS (Data Quality Health and Status)

- DQ HandS Plot Browser

- NCVweb: Interactive web-based tool for viewing ARM data

Plots of pulse energy provide a good indicator of whether the system is operational or not. 


\subsection{Data Reviews by Instrument Mentor}

Data reviews by the instrument mentor are performed monthly in conjunction with the Instrument Mentor Monthly Status (IMMS) report. Occasionally the raw data stream is inspected more frequently, particularly when instrument problems are brought to the attention of the mentor by on-site technicians.

\subsection{Data Assessments by Site Scientist/Data Quality Office}

All DQ Office and most Site Scientist techniques for checking have been incorporated within DQ HandS and can be viewed there.

\subsection{Value-Added Procedures}

SGPRL is a non-commercial research grade instrument. As such the only data products that are produced by the instrument itself are the raw return signals as defined by the sgprlC1.a0 data stream. The task of turning these raw measurements into scientifically useful information is currently handled by a suite of seven VAPs that were specifically developed for the RL by the ARM Program. A flow diagram that describes the sequence of data processing for the RL is shown in Figure 9. Also, Table 11 provides a listing of primary data products generated by each of the VAPs.

Currently, the first VAP that is executed is the so-called MERGE VAP. This VAP was added to the sequence after the installation of the new Licel transient data recorders in September of 2004. The Licel data recorders provide simultaneous measurements of analog photomultiplier voltage and photon counts. The MERGE VAP ingests these two signals, corrects for pulse pileup effects in the photon counting data, and optimally combines the photon counting signal with the analog signal to produce a single signal with improved dynamic range. The output from the MERGE VAP then serves as input to all the other RL VAPs, with the exception of the best estimate (BE) VAP. Prior to the installation of the Licel data recorders the SGPRL used pure photon counting electronics. Instead, the task of correcting for pulse pileup effects was performed separately by the ASR, EXT, MR and DEP VAPs.

The ASR and EXT VAP are typically run together, where the execution of the ASR VAP always precedes the execution of the EXT VAP, because the EXT VAP uses the volume backscatter coefficient generated by the ASR VAP to estimate extinction. In order to produce a final extinction data product the ASR and EXT VAPs are run in an iterative fashion. During the first pass execution of ASR and EXT, the ASR VAP is run with no differential aerosol transmission correction. This first-pass run is used to make any necessary updates to the overlap corrections. Once the overlap corrections have been updated, secondpass runs of the ASR and EXT VAP are performed using the updated overlap corrections, but again with no differential aerosol transmission correction applied to the ASR data. A third and final pass is then executed with differential aerosol transmission correction applied to the ASR.

Once a final aerosol extinction data product has been generated, the MR (mixing ratio) VAP is executed (with differential aerosol transmission correction). Once again, a first pass run is used to update the overlap corrections for the mixing ratio data. If the overlap correction requires updating, the MR VAP is then executed a second time using the updated overlap curves. 
The final stage in the whole RL VAP sequence involves the execution of the BE (best estimate) VAP. This VAP simply bundles the results from the ASR, EXT, MR, DEP and TEMP VAPs into a single output file. It is this output that is intended for use by the general science user community.

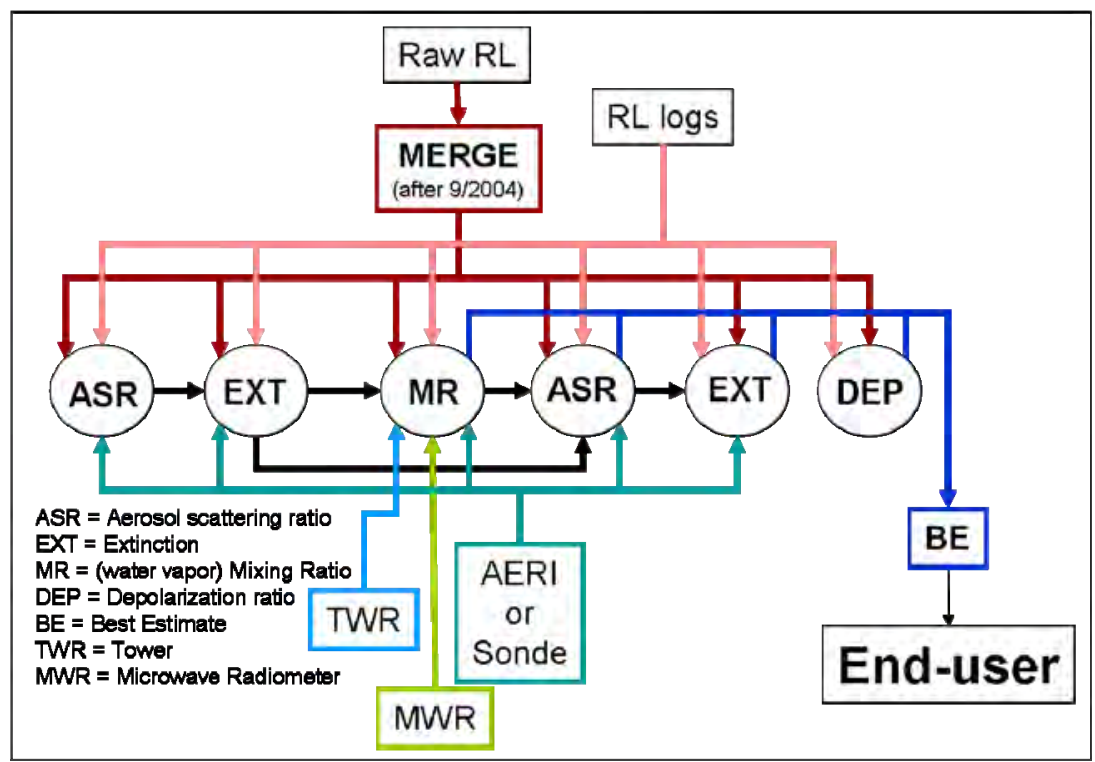

Figure 9. SGPRL VAP flow diagram.

Table 11. Primary data products generated by each of the RL VAPs.

\begin{tabular}{|l|rl|l|}
\hline \multicolumn{1}{|c|}{ VAP Name } & \multicolumn{2}{|c|}{ Primary Data Products } & \multicolumn{1}{c|}{ Status } \\
\hline Rlprofmerge & - & $\begin{array}{l}\text { Photon count rates for all 10 } \\
\text { detection channels }\end{array}$ & Operational \\
& - & Cloud base height & \\
\hline Rlprofasr & - & Aerosol scatter ratio & Operational \\
& - & Volume backscatter & \\
\hline Rlprofext & - & coefficient & Operosol extinction \\
& - & Aerosol optical depth & \\
\hline Rlprofmr & - & Water vapor mixing ratio & Operational \\
& - & Relative humidity, \\
& - & Precipitable water vapor & \\
\hline rlproftemp & - & Temperature & Under development \\
\hline
\end{tabular}

\subsection{Quality Measurement Experiments}

A special class of VAP called a Quality Measurement Experiment (QME) does not output geophysical parameters of scientific interest. Rather, a QME adds value to the input datastreams by providing for continuous assessment of the quality of the input data based on internal consistency checks, comparisons between independent similar measurements, or comparisons between measurement with modeled results, and so forth. For more information, see the VAPs and QMEs web page. 


\section{Instrument Details}

\subsection{Detailed Description}

\subsubsection{List of Components}

The diagram in Figure 10 shows the layout of the system inside the enclosure. Major commercially supplied components are listed in Table 12.

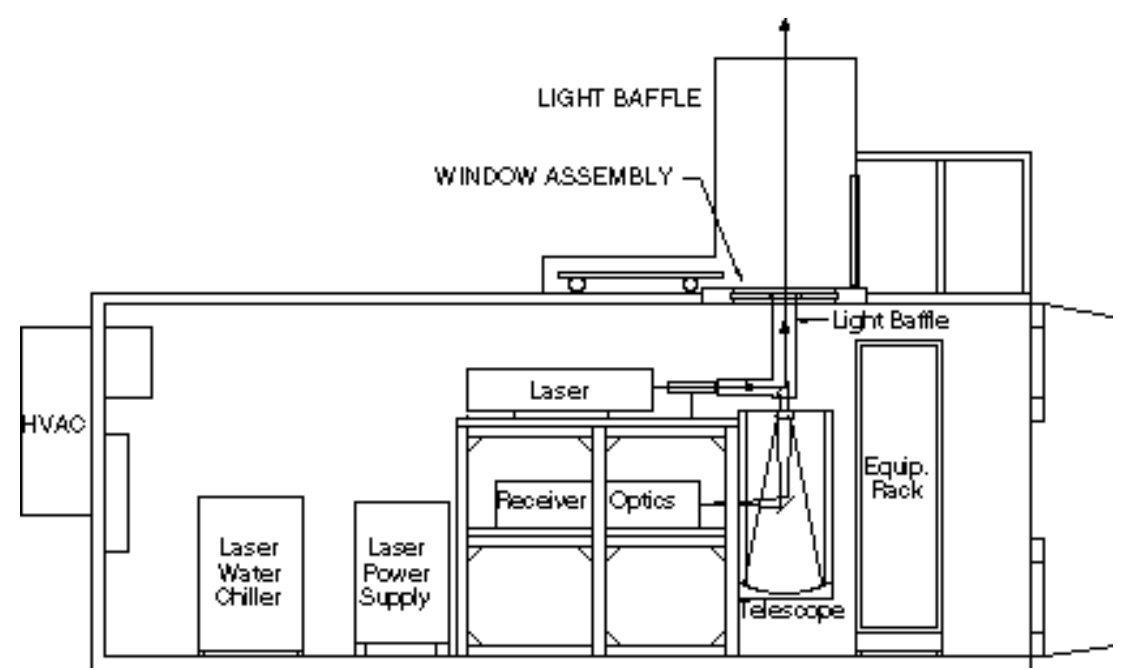

Figure 10. SGPRL enclosure and major components.

Table 12. Primary SGPRL system components.

\begin{tabular}{|c|l|}
\hline \multicolumn{1}{|c|}{ Item } & \multicolumn{1}{|c|}{ Manufacturer } \\
\hline Lidar enclosure & \\
\hline Basic lidar enclosure & Orca \\
\hline Air conditioners & \\
\hline Water chiller & KTS \\
\hline UPS & \\
\hline Transmit system & Continuum \\
\hline Nd:YAG Laser & \\
\hline Laser energy meter & \\
\hline Laser energy monitor & \\
\hline Beam director optics & \\
\hline Beam director mounts & \\
\hline Laser beam expander & Orca \\
\hline Final transmit mirror & \\
\hline Alignment module (after & Licel \\
\hline April 2007) & SRS \\
\hline Pulse generator & \\
\hline Receiver system & Optical Guidance Systems \\
\hline Receiving telescope & Barr \\
\hline Interference filters &
\end{tabular}


Table 12 (contd)

\begin{tabular}{|l|l|}
\hline \multicolumn{1}{|c|}{ Item } & \multicolumn{1}{|c|}{ Manufacturer } \\
\hline Dichroic mirrors & Barr \\
\hline Wedged beamspliter & Barr \\
\hline Polarizing beamsplitter & \\
\hline Other aft optics & \\
\hline Filter wheels & CVI \\
\hline Aft optics mounts & \\
\hline Photomultipliers & Electron Tubes (9954B) \\
\hline PMT housings & Electron Tubes \\
\hline HV supplies & LeCroy \\
\hline HeNe laser & \\
\hline Data acquisition & \\
\hline Data recorders & Licel \\
\hline Oscilloscope & Tektronix \\
\hline Computer & \\
\hline LabVIEW & National Instruments \\
\hline &
\end{tabular}

\subsubsection{System Configuration and Measurement Methods}

A schematic of the SGPRL receiver is shown in Figure 11. The telescope is shown on the left and the actual physical layout of the aft optics are shown on the right. Dichroic beam splitters are labeled "DBS" and "PBS" stand for polarizing beamsplitter. Narrowband filters are placed at the entrance of each PMT/tube assembly. The WFOV beam path is in red, and the NFOV beam path is in blue. We note that the boresight alignment module was not present prior to April 2007. Also, the two rotational Raman channels (T1 and T2), and the liquid water channel (LW) were added to the system in October 2005.

Light collected by the telescope is first split into two pieces by a wedged beam splitter, with $10 \%$ directed into the "short-range" wide-field-of-view channels, and 90\% into the "long-range" narrow-field-of-view channels. For each set of channels, the light first encounters an aperture (field stop), and is then collimated by field and collimating lenses. Dichroic beam splitters separate the light by wavelength into signals produced by backscatter from water vapor $(408 \mathrm{~nm})$, nitrogen $(387 \mathrm{~nm})$, and aerosol/Rayleigh scattering (355 nm, the laser wavelength), followed by narrow band interference filters, imaging lenses, and photo multipliers for each wavelength. In the "long-range" optics, a polarizing beam splitter is used to separately analyze the parallel and perpendicular polarization (relative to the laser beam) of the aerosol/Rayleigh scattering.

For system calibration purposes, computer-controlled filter wheels are used to replace the water-vapor and aerosol/Rayleigh filters by nitrogen filters. Signals recorded in this configuration can be used to determine any differences in the range dependence of the signals in the various channels, and to track the long-term relative sensitivity of the channels. 


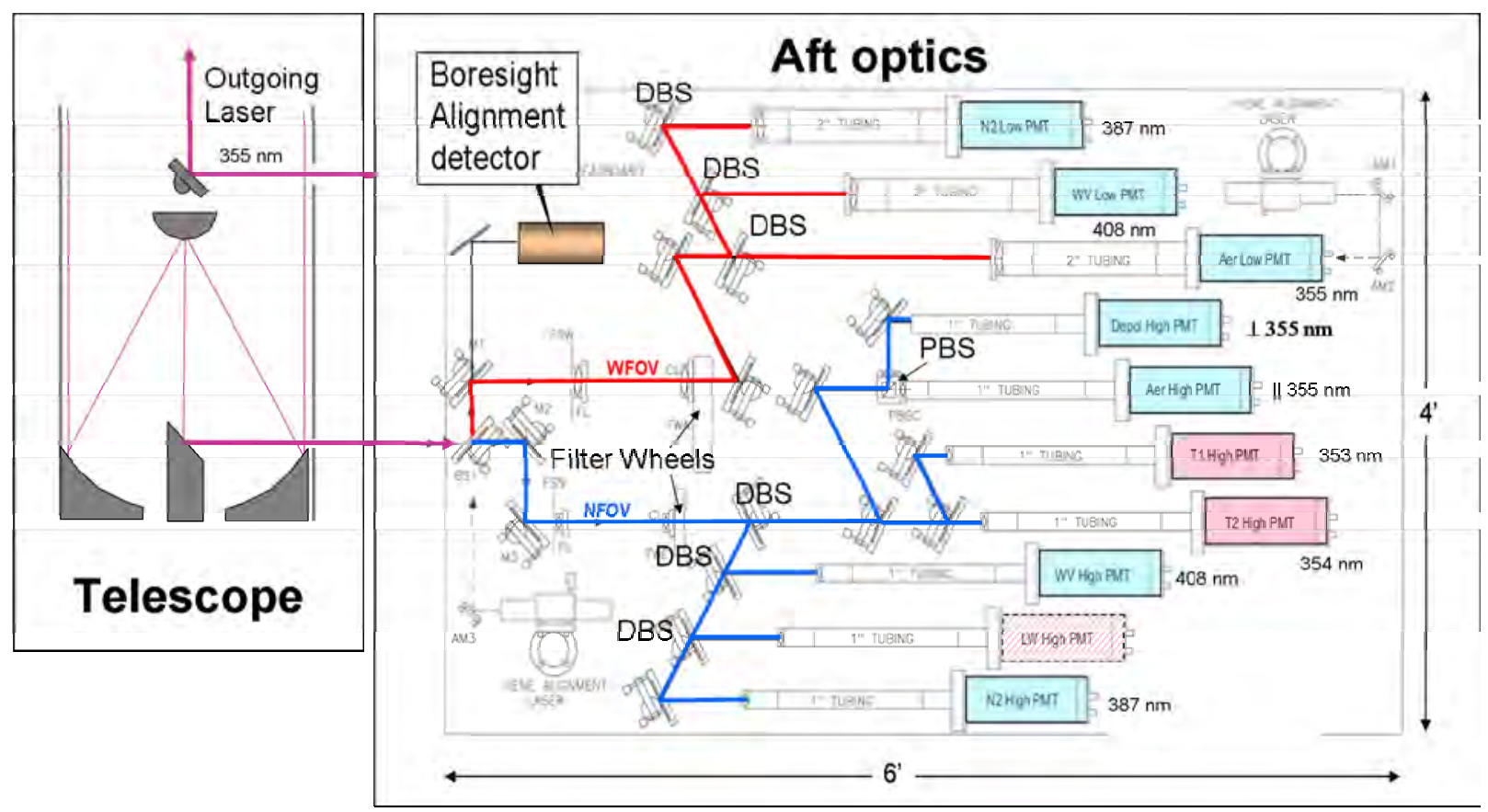

Figure 11. Schematic of the SGPRL receiver.

\subsubsection{Specifications}

The Table 13 lists the SGPRL system specifications. The system uses a tripled Nd:YAG laser, operating at $30 \mathrm{~Hz}$ with 300-400 millijoule pulses to transmit light at $355 \mathrm{~nm}$. A 61-cm diameter telescope collects the light backscattered by molecules and aerosols at the laser wavelength and the Raman scattered light from water vapor $(408 \mathrm{~nm})$ and nitrogen $(387 \mathrm{~nm})$ molecules. These signals are detected by photomultiplier tubes and recorded using photon counting with a vertical resolution of 7.5 meters (39 meters prior to September 2004). A beam expander reduces the laser beam divergence to $0.1 \mathrm{mrad}$, thereby permitting the use of a 0.3 -mrad NFOV as well as a 2-mrad WFOV. The NFOV, coupled with the use of narrowband ( $\sim .4 \mathrm{~nm}$ bandpass) filters, reduces the background skylight and, therefore, increases the maximum range of the aerosol and water vapor profiles measured during daytime operations. 
Table 13. SGPRL specifications.

\begin{tabular}{|c|c|}
\hline \multicolumn{2}{|c|}{ Transmitter } \\
\hline Laser & Tripled Nd:YAG \\
\hline Wavelength & $355 \mathrm{~nm}$ \\
\hline Pulse energy & $300-400 \mathrm{~mJ}$ \\
\hline Pulse repetition frequency & $30 \mathrm{~Hz}$ \\
\hline Beam diameter & $13 \mathrm{~cm}$ ( 0.1 mrad divergence) \\
\hline Bandwidth & $\sim 2 \mathrm{~cm}-1$ \\
\hline \multicolumn{2}{|c|}{ Receiver } \\
\hline Primary telescope diameter \& f\# & $61 \mathrm{~cm}, \mathrm{f} / 9.3$ \\
\hline Filter transmission & $30-40 \%$ \\
\hline \multicolumn{2}{|l|}{ Field of view } \\
\hline Wide (WFOV) & $2 \mathrm{mrad}$ \\
\hline Narrow (NFOV) & $0.3 \mathrm{mrad}$ \\
\hline \multicolumn{2}{|l|}{ Detection electronics } \\
\hline Before September 2004 & Photon counting w/39 m range resolution \\
\hline After September 2004 & $\begin{array}{l}\text { Simultaneous photon counting and analog w/7.5m range } \\
\text { resolution. }\end{array}$ \\
\hline \multicolumn{2}{|l|}{ Detection channels } \\
\hline Unpolarized elastic (WFOV) & Wavelength $=355 \mathrm{~nm}$ \\
\hline Beam parallel elastic (NFOV) & Wavelength = $355 \mathrm{~nm}$ \\
\hline Beam perpendicular elastic (NFOV) & Wavelength $=355 \mathrm{~nm}$ \\
\hline Water vapor (WFOV \& NFOV) & Wavelength $=408 \mathrm{~nm}$ \\
\hline Nitrogen (WFOV \& NFOV) & Wavelength $=387 \mathrm{~nm}$ \\
\hline Temperature (NFOV) & Wavelength $=353 \mathrm{~nm}$ \\
\hline Temperature (NFOV) & Wavelength $=355 \mathrm{~nm}$ \\
\hline Liquid Water (NFOV) & Wavelength $=? \mathrm{~nm}$ \\
\hline
\end{tabular}

\subsection{Theory of Operation}

The SGPRL operates by transmitting pulses of laser radiation at a wavelength of $\lambda_{o}=355 \mathrm{~nm}$, and recording radiation backscattered from the atmosphere as a function of time to provide range information similar to a radar system. The return signal contains a strong elastically scattered component (at $\lambda_{o}$ ) due to scattering from clouds, aerosols, and molecular Rayleigh scattering. The return also contains weaker inelastically scattered components that provide chemical-specific information. Selected species are detected by measuring the wavelength-shifted molecular return produced by Raman scattering, as illustrated in Figure 12. 


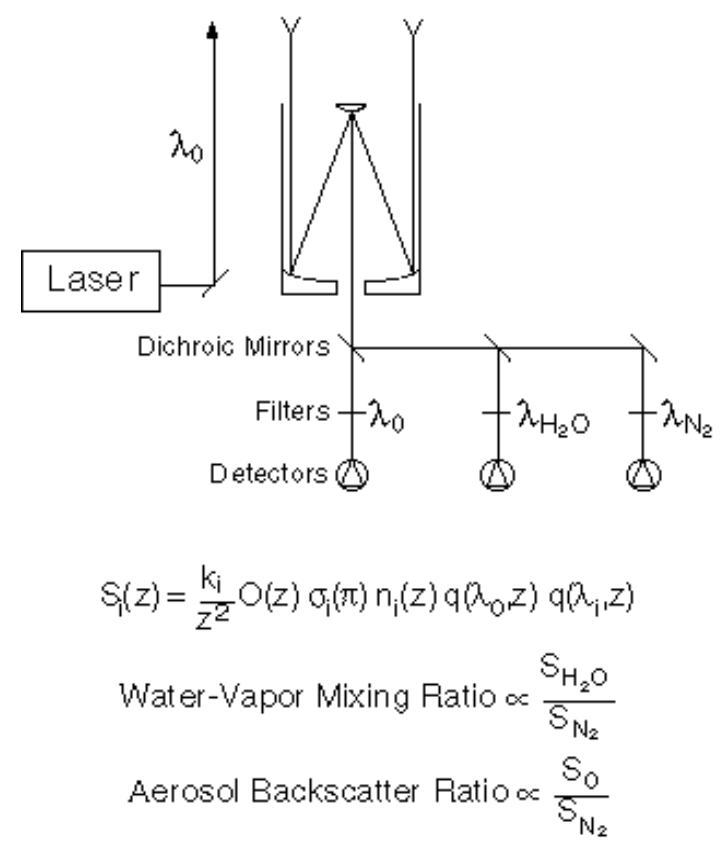

Figure 12. Schematic of the theory of operation of the Raman lidar.

For the $i^{\text {th }}$ detection channel the return signal is inversely proportional to range squared, $z^{2}$, and proportional to the product of constant a, $k_{i}$, overlap function $O(z)$, Raman backscatter cross-section $\sigma_{i}$, number density $n_{i}(z)$, one-way attenuation of the laser beam at $\lambda_{o}, q\left(\lambda_{o}, z\right)$, and the one-way attenuation of the backscattered radiation at $\lambda_{i}, q\left(\lambda_{i}, z\right)$.

By taking the ratio of the signal at the water-vapor wavelength $(408 \mathrm{~nm})$ to the signal at the nitrogen wavelength (387 nm), most of the range-dependent terms drop out, and one is left with a quantity that is almost directly proportional to the water-vapor mixing ratio expressed as grams of water vapor per kilogram of dry air (a small correction for the wavelength dependence of the second attenuation term is easily taken into account). Similarly, by taking the ratio of the signal at the laser wavelength to the signal at the nitrogen wavelength, one is left with the aerosol backscatter ratio; this ratio is normalized such that it is unity in "clean air" (laser-wavelength scatter caused only by Rayleigh scattering), and is in excess of unity for scattering by parcels of air that contain aerosols (including cloud droplets/particles). Finally, analysis of the polarization dependence of the backscatter signal at the laser wavelength provides information on particle shape (phase); spherical particles (cloud droplets) do not depolarize the laser backscatter, whereas nonspherical particles (such as ice crystals in cirrus clouds) can significantly depolarize the laser backscatter.

Narrow band, NFOVoperation provides good daytime performance (discrimination of the weak Raman backscatter signal above the background daylight) without sacrificing nighttime performance. The SGPRL has been implemented as a dual field-of-view instrument because NFOVoperation provides very weak short-range signals. A set of WFOVchannels provides better results for short-range signals (out to $\sim 500 \mathrm{~m}$ for water vapor). 


\subsection{Calibration}

\subsubsection{Theory}

Each of the primary variables produced by the various RL VAPs require calibration. Details concerning the calibration of a specific primary variable can be obtained by accessing the following VAP webpages:

- $\quad$ Rlprof_mr (water vapor mixing ratio)

- $\quad$ Rlprof_asr (aerosol scattering ratio)

- Rlprof_ext (aerosol extinction)

- $\quad$ Rlprof dep (aerosol depolarization ratio)

\subsubsection{Procedures}

See section 7.3.1.

\subsubsection{History}

This section is under development.

\subsection{Operation and Maintenance}

\subsubsection{User Manual}

The SGPRL operation manual is available from SGP site-ops personnel.

\subsubsection{Routine and Corrective Maintenance Documentation}

Routine and corrective maintenance documentation is maintained by the SGPRL on-site technician. Daily instrument logs can be viewed by accessing SGPRL instrument logs. Note that access to this site requires prior approval from the site manager.

\subsubsection{Software Documentation}

Raw Raman lidar data are ingested at the Data Management Facility (DMF), creating netCDF a1 level data files, which are stored in the ACRF Archive. Information on data file formats is available in Section 5, Data Description and Examples.

\subsubsection{Additional Documentation}

This section is under development.

\subsection{Glossary}

See the ARM Glossary. 


\subsection{Acronyms}

ACRF ARM Climate Research Facility

AGL above ground level

ARM Atmospheric Radiation Measurement (Program)

CARL CART Raman Lidar (Same as SGPRL)

DMF Data Management Facility

DOE: U.S. Department of Energy

DQO Data Quality Office

ETL Environment Technology Laboratory (NOAA)

IOP Intensive Operational Period

LIDAR light detection and ranging

MMCR millimeter cloud radar

NOAA: National Oceanic and Atmospheric Administration

NSA North Slope of Alaska

PNNL Pacific Northwest National Laboratory (Battelle)

PMT Photon multiplier tude

QME Quality Measurement Experiment

RF radio frequency

SDS site data system

SGP Southern Great Plains

SGPRL Southern Great Plains Raman Lidar

VAP value-added procedure

Also see the ARM Acronyms and Abbreviations.

\section{References}

Ansmann, A, M Riebesell, U Wandinger, C Weitkamp, E Voss, W Lahmann, and W Michaelis. 1992. "Combined Raman elastic-backscatter lidar for vertical profiling of moisture, aerosol extinction, and lidar ratio,” Journal of Applied Physics B55: 18-28.

Ferrare, RA, DD Turner, M Clayton, B Schmid, J Redemann, D Covert, R Elleman, J Ogren, E Andrews, JEM Goldsmith, and H Johsson. 2006 . "Evaluation of daytime measurements of aerosols and water vapor made by an operational Raman lidar over the Southern Great Plains.” Journal of Geophysical Research 111: D05S08, doi:10.1029/2005JD005836.

Goldsmith, JEM, FH Blair, SE Bisson, and DD Turner. 1998. "Turn-key Raman lidar for profiling atmospheric water vapor, clouds, and aerosols.” Applied Optics 37(21): 4979-4990. 
Newsom, RK, DD Turner, M Clayton, and R Ferrare. 2008. "Progress on the use of combined analog and photon counting detection for Raman lidar.” Preprints of the 24rd International Laser Radar Conference, Boulder, CO, USA.

Newsom, RK, DD Turner, B Mielke, M Clayton, RA Ferrare, and C Sivaraman. 2009. "Use of Simultaneous analog and photon counting detection for Raman Lidar.” Submitted to Applied Optics.

Petty, D, and DD Turner. 2006. "Combine analog-to-digital and photon counting detection utilized for continuous Raman lidar measurements.” Preprints of the 23rd International Laser Radar Conference, Nara, Japan.

Russo, F, DN Whiteman, DD Turner, and RM Hoff. 2008. "Measurements of the aerosol indirect effect using a Raman lidar.” Journal of Geophysical Research in preparation.

Stokes, GM, and SE Schwartz. 1994. "The Atmospheric Radiation Measurement (ARM) Program: Programmatic background and design of the cloud and radiation test bed.” Bulletin of the American Meteorological Society 75:-1221.

Turner, DD, and JEM Goldsmith. 1999. “Twenty-four-hour Raman lidar water vapor measurements during the Atmospheric Radiation Measurement Program’s 1996 and 1997 water vapor intensive observation periods.” Journal of Atmospheric and Oceanic Technology 16: 1062-1076.

Turner, DD, WF Feltz, and RA Ferrare. 2000. “Continuous water vapor profiles from operational active and passive remote sensors.” Bulletin of the American Meteorological Society 81: 1301-1317.

Turner, DD, RA Ferrare, LA Heilman Brasseur, WF Feltz, TP Tooman. 2002. “Automated retrievals of water vapor and aerosol profiles from an operational Raman lidar." Journal of Atmospheric and Oceanic Technology 19: 37-49.

Turner, DD, BM Lesht, SA Clough, JC Liljegren, HE Revercomb, and DC Tobin. 2003. "Dry bias and variability in Vaisala radiosondes: The ARM experience.” Journal of Atmospheric and Oceanic Technology 20: 117-132.

Turner, DD, and JEM Goldsmith. 2005. "Refurbishment and upgrade of the Atmospheric Radiation Measurement Raman lidar.” Paper presented at the $15^{\text {th }}$ ARM Science Team Meeting, U.S. Department of Energy, Daytona Beach, Florida.

Turner, DD, RA Ferrare, JEM Goldsmith, D Petty, MB Clayton, LA Brasseur, T Tooman, Z Wang, and JM Comstock. 2006. "A decade of Raman lidar water vapor, aerosol, and cloud observations at the ARM Southern Great Plains Site.” $3^{\text {rd }}$ Symposium on Lidar Atmospheric Applications, AMS annual meeting, San Antonio, Texas.

Whiteman, DN, SH Melfi, and RA Ferrare. 1992. "Raman lidar system for the measurement of water vapor and aerosols in the Earth’s atmosphere.” Applied Optics 31: 3068-3082. 
Whiteman, DN, B Demoz, P Di Girolamo, J Comer, I Veselovskii, K Evans, Z Wang, M Cadirola, K Rush, G Schwemmer, B Gentry, SH Melfi, B Mielke, D Venable, and T Van Hove. 2006. "Raman lidar measurements during the International $\mathrm{H}_{2} \mathrm{O}$ Project. Part 1: Instrumentation and analysis techniques.” Journal of Atmospheric and Oceanic Technology 23(2): 157-169. 